\title{
The Relationship between Neck Size of the Cerebral Saccular Aneurysms and Outcome after Endovascular Intervention
}

\author{
AHMED M. DEABES, M.Sc.; FATHY H. EL-NOSS, M.D.; HOSSAM I. MAATY, M.D.; \\ AHMED A. ARAB, M.D. and MOHAMED N. SHADAD, M.D. \\ The Department of Neurosurgery, Faculty of Medicine, Benha University, Benha, Egypt
}

\begin{abstract}
Background: Intracranial aneurysms are common with a prevalence of $0.2 \%$ to $9 \%$ in adults. Intracranial aneurysms have high mortality and morbidity, so exclusion of aneurysms from cerebral circulation is aimed with established endovascular embolization.

Aim of Study: Is to report our experience in managing intracranial aneurysms using coil embolization and to report the relation between neck size of cerebral aneurysms, its relation to dome height which is defined as Aspect Ratio (AR), and clinical, angiographic outcome after endovascular intervention.

Patients and Methods: From July 2015 to May 2017, a series of 40 nonrandomized consecutive patients (mean age: $44.2 \pm 14.9$ years) with 42 intracranial aneurysms underwent endovascular coil embolization in our center. We excluded patients with $\mathrm{H} \& \mathrm{H}$ grade 5 on admission and patients with $\mathrm{H} \& \mathrm{H}$ grade 4 were managed conservatively until improvement with better H\&H grade. All patients were evaluated by four-vessel angiography to determine the shape, size, number and location of the aneurysms. Degree of aneurysm occlusion were assessed according to modified Raymond Roy classification. The cases were divided according to neck size, $4 \mathrm{~mm}$ being the discriminative value for small and wide necks and divided according to aspect ratio into AR $>2$, AR 1.5-2, AR $1-1.5, \mathrm{AR}<1$. The post coiling angiogram of each case was analyzed to evaluate the degree of occlusion achieved by the technique, clinical outcome was assessed by Glasgow Outcome Scale (GOS).
\end{abstract}

Results: Immediately after the procedure, Raymond class I with total occlusion was seen in $26(61.9 \%)$, Raymond class II with subtotal occlusion in $10(23.8 \%)$, and incomplete occlusion with Raymond class IIIa in $4(9.5 \%)$ and Raymond class IIIb in $2(4.8 \%)$ aneurysms. There was significant relationship between the aneurysm neck size and aspect ratio with degree of occlusion. In the small necked groupand AR $>1.5$ with modified Raymond classification are; class I was achieved in $22(68.8 \%)$ aneurysms, class II in $8(25 \%)$ aneurysms, class IIIa in one (3.1\%) aneurysm, class IIIb in one $(3.1 \%)$ aneurysm. The wide necked group and $\mathrm{AR}<1.5$ provides different results, class I was achieved in $4(40 \%)$ aneu-

Correspondence to: Dr. Ahmed A. Daebes, E-Mail: drahmoh2@gmail.com. rysms, class II in $2(20 \%)$ patients, class IIIa in $3(30 \%)$ aneurysms and class IIIb in one (10\%) aneurysm. Six patients $(15 \%)$ experienced some complication during the procedure, including two aneurysms perforation, two thromboembolic events and two device induced vasospasm. Thirty four patients with 36 aneurysms who underwent follow-up for 6 months, $29(80.6 \%)$ aneurysms with no change, five $(13.8 \%)$ had recanalization and two $(5.6 \%)$ had more thrombosis.

Conclusion: Endovascular coiling was an effective and safe technique for treatment of cerebral aneurysms showing a high cure rate as a single treatment modality in aneurysms with small neck size and AR $>1.5$, but in aneurysms with wide neck and $\mathrm{AR}<1.5$, it is beneficial when assisted with additional forms of endovascular intervention (balloon, stent or flow diverters) for better treatment and improving outcome of the cases. Low aspect ratio plays a more dominant role than neck diameter in predicting the need for adjunctive techniques in the coiling of intracranial aneurysms.

Key Words: Intracranial aneurysms - Endovascular intervention-Aspect ratio - Neck size.

\section{Introduction}

ANEURYSM is a persistent localized dilatation of the vessel wall, usually an artery. Saccular aneurysms account for the vast majority (98\%) of all intracranial aneurysms, and the word aneurysm in this work refers to this form. Other types of aneurysms are fusiform, dissecting, infectious (mycotic) and traumatic aneurysms. Aneurysms commonly arise at the branching site of major

\footnotetext{
Abbreviation:

$\mathrm{H} \& \mathrm{H} \quad$ : Hunt and Hiss).

GOS : Glasgow Outcome Scale.

AR : Aspect Ratio).

GCS : Glasgow Coma Scale.

MRA : MR Angiography.

DSA : Digital Subtraction Angiography.

MCA : Middle Cerebral Artery.

ICA : Internal Carotid Artery.

A com A : Anterior communicating Artery.

P com A : Posterior Communicating Artery.
} 
arteries. It also occurs at a turn or curve of the artery, and points in the direction that the blood would have gone [1]. Saccular aneurysms consist of three main regions: Neck, sac and dome, assessments of aneurysm geometry and its effect on treatment decisions and treatment outcomes have been in use. The most common and well-studied geometric determinants of treatment decision and outcome have been the aspect ratio (dome height to neck) and neck width. Understanding the natural history of aneurysms is important in making treatment decisions [2]. In 1991, Guido Guglielmi was the first to describe the technique of occluding aneurysms from an endovascular approach with electrolytic detachable platinum coils, termed Guglielmi Detachable Coils (GDCs). GDCs are introduced directly into the aneurysm through a microcatheter and detached from a stainless-steel micro guide wire by an electrical current [3] .

\section{Patients and Methods}

From July 2015 to May 2017, a series of 40 patients with 42 intracranial aneurysms who were referred, to underwent endovascular coil embolization in our center. The mean age of our patients was $44.25 \pm 14.9$ (23-65) years. This study was approved by our institutional review board. Written informed consent was obtained from all patients.

There were 40 patients, 8 patients presented with mass effect due to un ruptured aneurysms, GCS were used for assessment in pre and immediate post intervention, and GOS at hospital discharge, after 6 months. 32 patients presented with ruptured aneurysms, $\mathrm{H} \& \mathrm{H}$ scale used for assessment in pre and immediate post intervention, and GOS at hospital discharge, after 6 months.

Patients with dissecting, or fusiform aneurysms and patients with $\mathrm{H} \& \mathrm{H}$ grade 5 were excluded from the study, patients with $\mathrm{H} \& \mathrm{H}$ grade 4 were managed conservatively till improvement of $\mathrm{H} \&$ $\mathrm{H}$ scale. Initially, all the patients were evaluated by $\mathrm{CT}$ brain then $\mathrm{CT}$ angiography or MRA were done then four-vessel angiography to determine the shape, size, and location of the aneurysms and to decide about the therapeutic protocol. Thereafter, microcatheter was used with a guiding catheter to place the optimal coils in the aneurysm region. First, the 3D helix coil was introduced and thereafter, 2D helix and soft coils were introduced in the aneurysm. In our study, due to financial issues and available materials, single microcatheter were used in 34 aneurysms, double microcatheter in 4 patients and 2 aneurysms with balloon assisted technique.
Post embolization angiography was done to evaluate the effect of aneurysm occlusion, the blood flow of the artery and its intracranial branches and the patients were divided into three groups according to modified Raymond Roy classification: class I with total occlusion, class II with subtotal occlusion, and class III with incomplete occlusion then subdivided into class IIIa and class IIIb. After six months, follow-up by MRA or DSA in selected cases, 34 patients with 36 aneurysms had been evaluated for recanalization, further occlusion, or still stationary.

\section{Results}

Demographic and presentation data: Collected in (Table 1).

Table (1): Demographic and presentation data of patients with intracranial aneurysms treated by coiling.

\begin{tabular}{|c|c|}
\hline Characteristics & No. $(\%)$ \\
\hline \multicolumn{2}{|l|}{ Gender: } \\
\hline Female & $22(55)$ \\
\hline Male & $18(45)$ \\
\hline \multicolumn{2}{|l|}{ Age distribution: } \\
\hline$<30 y$ & $1 \quad(2.5)$ \\
\hline $30-40 y$ & $3 \quad(7.5)$ \\
\hline $40-50 y$ & $21(52.5)$ \\
\hline $50-60 y$ & $13(32.5)$ \\
\hline$>60 y$ & $2(5)$ \\
\hline \multicolumn{2}{|c|}{ Medical history \& smoking: } \\
\hline Smoking & $8 \quad(20)$ \\
\hline Hypertension & $9 \quad(22.5)$ \\
\hline Diabetes mellitus & $6 \quad(15)$ \\
\hline HTN \& DM & $4 \quad(10)$ \\
\hline Free medical history & $21(52.5)$ \\
\hline \multicolumn{2}{|l|}{ Clinical presentation: } \\
\hline \multicolumn{2}{|l|}{ A- Unruptured aneurysms: } \\
\hline Visual field defect & $2(5)$ \\
\hline 6th nerve palsy & $3 \quad(7.5)$ \\
\hline 3 rd nerve palsy & $3 \quad(7.5)$ \\
\hline \multicolumn{2}{|l|}{ B- Ruptured aneurysms: } \\
\hline $\mathrm{H} \& \mathrm{H}$ grade 1 & $8 \quad(20)$ \\
\hline $\mathrm{H} \& \mathrm{H}$ grade 2 & $11(27.5)$ \\
\hline $\mathrm{H} \& \mathrm{H}$ grade 3 & $9 \quad(22.5)$ \\
\hline $\mathrm{H} \& \mathrm{H}$ grade 4 & $4 \quad(10)$ \\
\hline H\&H grade 5 & $0 \quad(0)$ \\
\hline \multicolumn{2}{|c|}{$\begin{array}{l}\text { CT brain findings with modified } \\
\text { fisher grades: }\end{array}$} \\
\hline Grade 0 & $8 \quad(20)$ \\
\hline Grade 1 & $9 \quad(22.5)$ \\
\hline Grade 2 & $11(27.5)$ \\
\hline Grade 3 & $7 \quad(17.5)$ \\
\hline Grade 4 & $5 \quad(12.5)$ \\
\hline
\end{tabular}

Abbreviations: $\mathrm{H} \& \mathrm{H}$ : Hunt and hiss grades. 
Characteristics of aneurysms treated: Collected in (Table 2).

Table (2): Characteristics of aneurysms according to angiography.

\begin{tabular}{|c|c|}
\hline Characteristics & No. $(\%)$ \\
\hline $\begin{array}{l}\text { Location: } \\
\text { A- Anterior circulation: } \\
\text { A com A } \\
\text { ICA } \\
\text { MCA } \\
\text { P com A } \\
\text { Anterior choroidal artery } \\
\text { Ophthalmic artery }\end{array}$ & $\begin{array}{ll}16 & (38.4) \\
1 & (2.4) \\
8 & (19.2) \\
12 & (28.8) \\
1 & (2.4) \\
1 & (2.4)\end{array}$ \\
\hline $\begin{array}{l}\text { B- Posterior circulation: } \\
\text { Basilar artery } \\
\text { PICA }\end{array}$ & $\begin{array}{ll}1 & (2.4) \\
2 & (4.8)\end{array}$ \\
\hline $\begin{array}{l}\text { Integrity of aneurysm: } \\
\text { A- Ruptured aneurysms } \\
\text { B- Un ruptured aneurysms }\end{array}$ & $\begin{array}{l}32(76.2) \\
10(23.8)\end{array}$ \\
\hline $\begin{array}{l}\text { Number of aneurysms treated per patient: } \\
\text { One aneurysm } \\
\text { Double aneurysms }\end{array}$ & $\begin{array}{lc}38 & (90.4) \\
4 & (9.6)\end{array}$ \\
\hline $\begin{array}{l}\text { Size of aneurysms: } \\
\text { A- According to neck size: } \\
\quad>4 \mathrm{~mm} \\
\quad<4 \mathrm{~mm}\end{array}$ & $\begin{array}{l}10(23.8) \\
32(76.2)\end{array}$ \\
\hline $\begin{array}{l}\text { B- According to aspect ratio: } \\
\text { AR }>2 \\
\text { AR } 1.5-2 \\
\text { AR } 1-1.5 \\
\text { AR }<1\end{array}$ & $\begin{array}{ll}19 & (45.2) \\
17 & (40.5) \\
6 & (14.3) \\
0 & (0)\end{array}$ \\
\hline 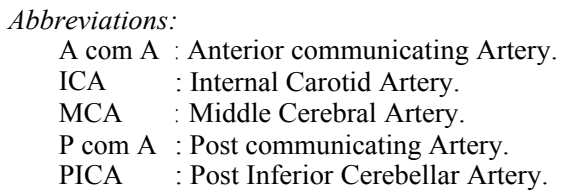 & \\
\hline
\end{tabular}

Coiling results: In 40 patients with 42 aneurysms, the procedures were performed under general anesthesia. 34 aneurysms were coiled by single catheter, 4 aneurysms by double catheter, and 2 aneurysms by balloon assisted technique. No stents or flow diverters were used in this study. Degree of aneurysm occlusion were assessed by modified Raymond Roy classification which had shown class I in 26 aneurysms, class II in 10 aneurysms, class IIIa in 4 aneurysms, and class IIIb in 2 patients. These results are subdivided according to neck size and aspect ratio in (Table 3 ).

Complications: Six patients (15\%) experienced complication during the procedure including two aneurysms perforation, two thromboembolic events, and two arterial device induced vasospasm. There was no mortality during the procedure. Most complications passed smoothly as (Table 4).

Angiographic follow-up: Among 34 patients with 36 aneurysms who underwent follow-up angiography after 6 months, 29 aneurysms $(80.6 \%)$ had no change, five $(13.8 \%)$ had recanalization and two $(5.6 \%)$ had further occlusion. 5 patients were missed and 1 patient were dead (Table 5).

Pre discharge outcome: Good outcome (GOS 5) was achieved in $28(70 \%)$ patients, six patients $(15 \%)$ had moderate disability (GOS 4), 4 (10\%) patients with severe disability (GOS 3), one (2.5\%) patient were vegetative state (GOS 2) and one $(2.5 \%)$ patient were dead (GOS 1$)$.

Table (3): Occlusion degree according to neck size and aspect ratio.

\begin{tabular}{|c|c|c|c|c|c|c|c|c|c|c|c|c|}
\hline \multirow{3}{*}{$\begin{array}{l}\text { Occlusion } \\
\text { degree }\end{array}$} & \multicolumn{4}{|c|}{ Neck size of aneurysm } & \multicolumn{6}{|c|}{ Aspect ratio (AR) } & \multirow{2}{*}{\multicolumn{2}{|c|}{ Total }} \\
\hline & \multicolumn{2}{|c|}{$<4 \mathrm{~mm}$} & \multicolumn{2}{|c|}{$>4 \mathrm{~mm}$} & \multicolumn{2}{|c|}{$\mathrm{AR}>2$} & \multicolumn{2}{|c|}{ AR $1.5-2$} & \multicolumn{2}{|c|}{ AR $1-1.5$} & & \\
\hline & 22 & $68.75 \%$ & 4 & $40 \%$ & 15 & $79 \%$ & 9 & $52.9 \%$ & 2 & $33.3 \%$ & 26 & $61.9 \%$ \\
\hline Class II & 8 & $25 \%$ & 2 & $20 \%$ & 2 & $10.5 \%$ & 6 & $35.3 \%$ & 2 & $33.3 \%$ & 10 & $23.8 \%$ \\
\hline Class IIIa & 1 & $3.1 \%$ & 3 & $30 \%$ & 2 & $10.5 \%$ & 1 & $5.9 \%$ & 1 & $16.7 \%$ & 4 & $9.5 \%$ \\
\hline Class IIIb & 1 & $3.1 \%$ & 1 & $10 \%$ & 0 & $0 \%$ & 1 & $5.9 \%$ & 1 & $16.7 \%$ & 2 & $4.8 \%$ \\
\hline Total & 32 & $100 \%$ & 10 & $100 \%$ & 19 & $100 \%$ & 17 & $100 \%$ & 6 & $100 \%$ & 42 & $100 \%$ \\
\hline
\end{tabular}

Table (4): Procedural complications and outcome.

\begin{tabular}{lccccc}
\hline \multirow{2}{*}{ Complications } & No. of patients & \multicolumn{3}{c}{ Complication outcome } \\
\cline { 3 - 6 } & & No deficits & Transient morbidity & Permanent morbidity & Mortality \\
\hline Vasospasm & 2 & 2 & 0 & 0 & 0 \\
Aneurysm perforation & 2 & 1 & 1 & 1 & 0 \\
Thromboembolic events & 2 & 1 & 0 & 1 & 0 \\
\hline Total & 6 & 4 & 1 & 0 \\
\hline
\end{tabular}


Table (5): Angiographic follow-up after 3 and 6 months.

\begin{tabular}{|c|c|c|c|}
\hline Aneurysms & Initial occlusion degree & (3) months follow-up & (6) months follow-up \\
\hline \multirow[t]{3}{*}{ (8) Unruptured aneurysms in 8 patients } & 6 class I & Not included & 6 class I \\
\hline & 2 class II & & 1 class II \\
\hline & & & 1 missed \\
\hline \multirow{6}{*}{$\begin{array}{l}\text { (32) Ruptured aneurysms + } \\
\text { (2) Unruptured in } 32 \text { patients }\end{array}$} & 20 class I & 20 class I & 19 class I \\
\hline & 8 class II & 7 class II & 6 class II \\
\hline & 4 class IIIa & 5 class IIIa & 3 class IIIa \\
\hline & 2 class IIIb & 1 class IIIb & 1 class IIIb \\
\hline & & 1 dead & 1 dead \\
\hline & & & 4 missed \\
\hline
\end{tabular}
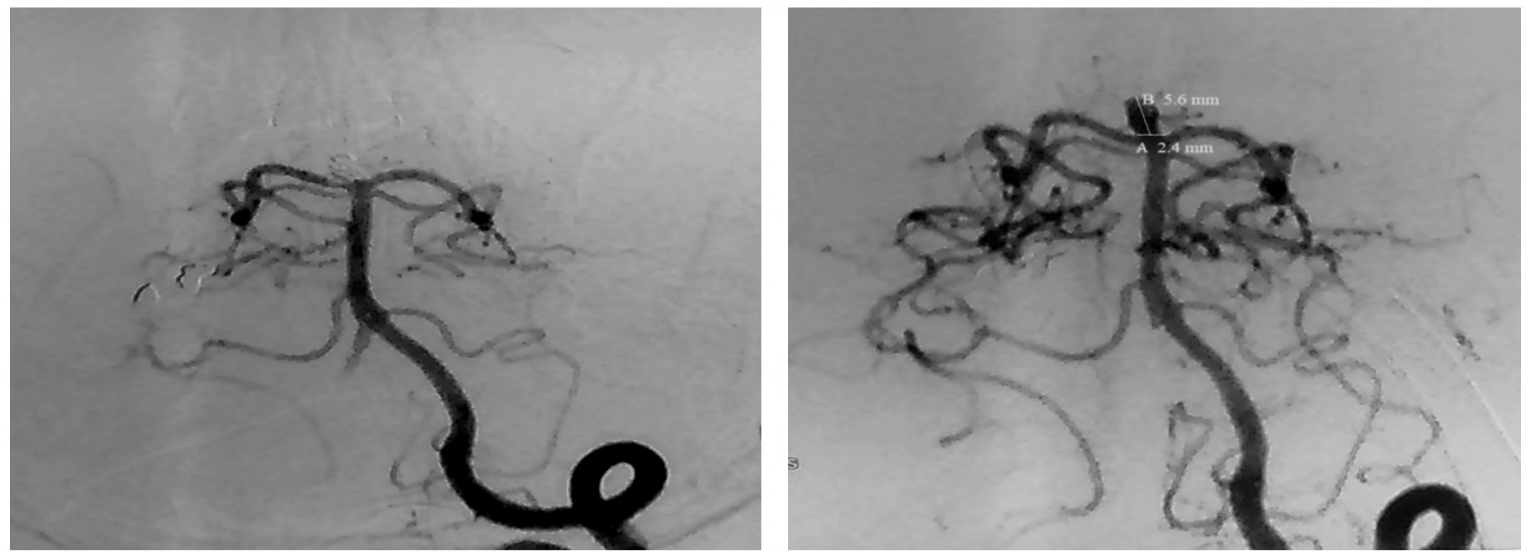

Case (1): A male patient aged 50 years, presented by sudden severe headache and disturbed conscious level (GCS 12). CT brain showed massive SAH with intraventricular extension (modified fisher grade 3). CT brain angiography showed basilar tip aneurysm.Catheter angiography is done with measuring aneurysm neck diameter about $2.4 \mathrm{~mm}$, dome height $5.6 \mathrm{~mm}$ and aspect ratio 2.3, patient is managed with simple coiling by single microcatheter with complete closure of aneurysm. Patient discharged with GOS grade 4.
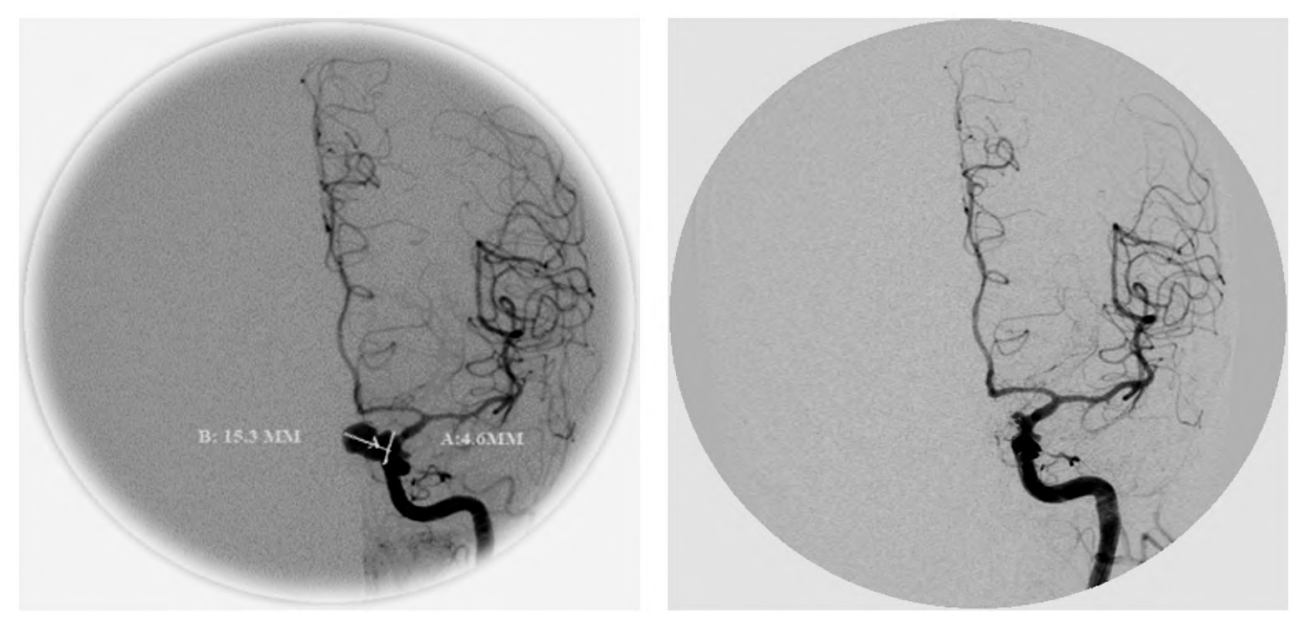

Case (2): A female patient aged 48 years, presented with severe headache and disturbed conscious level (GCS 14). CT brain shows SAH in basal cistern (modified fisher grade 1), with more deterioration of conscious level (GCS 11), follow-up CT brain shows rebleeding with more extensive SAH and intraventricular haemorrhage (modified fisher grade 4). CT angiography shows large P Com artery aneurysm, then catheter angiography is done showing aneurysm neck size $(4.6 \mathrm{~mm})$, dome height $14.6 \mathrm{~mm}$ and aspect ratio 3.6. Simple coiling is done with subtotal occlusion of neck aneurysm. patient discharged with GOS grade 3. 

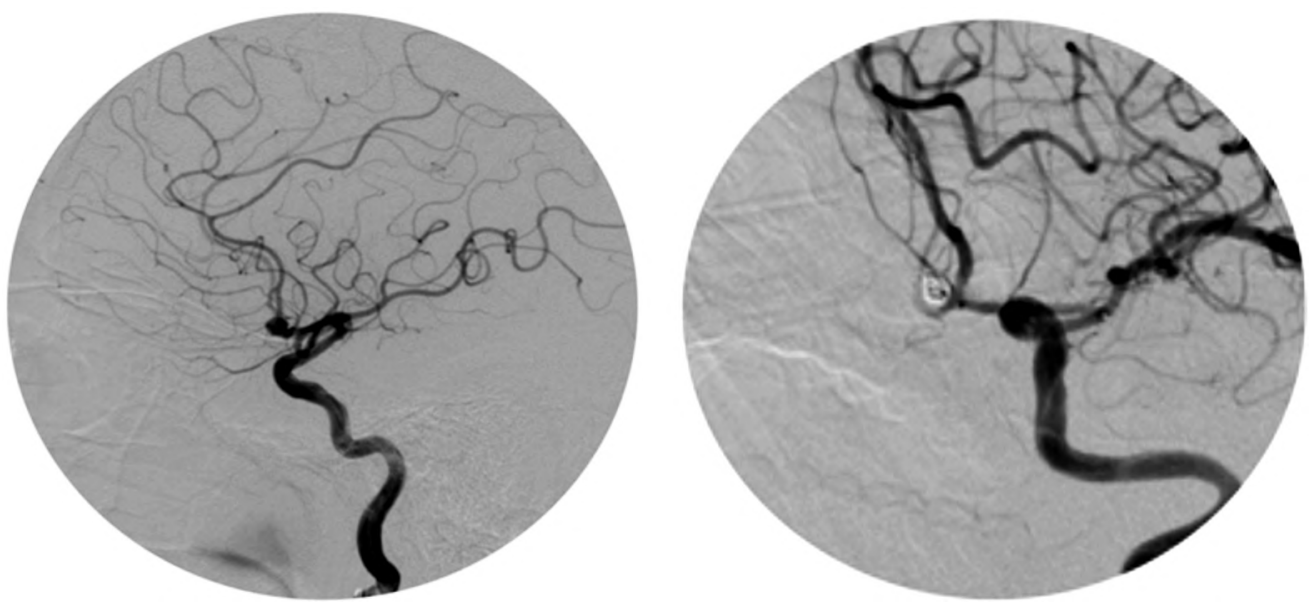

Case (3): A male patient aged 54 years, known to be diabetic presented by sudden severe headache, disturbed conscious level (GCS 13). CT brain showed SAH (modified fisher grade 1) and CT brain angiography showed anterior communicating artery aneurysm. Catheter angiography is done with measuring aneurysm neck diameter about $3.4 \mathrm{~mm}$, dome height $4.8 \mathrm{~mm}$ and aspect ratio 1.4 patient is managed by double microcatheter coiling with complete occlusion Raymond class 1 of aneurysm. patient discharged with good GOS grade 5.
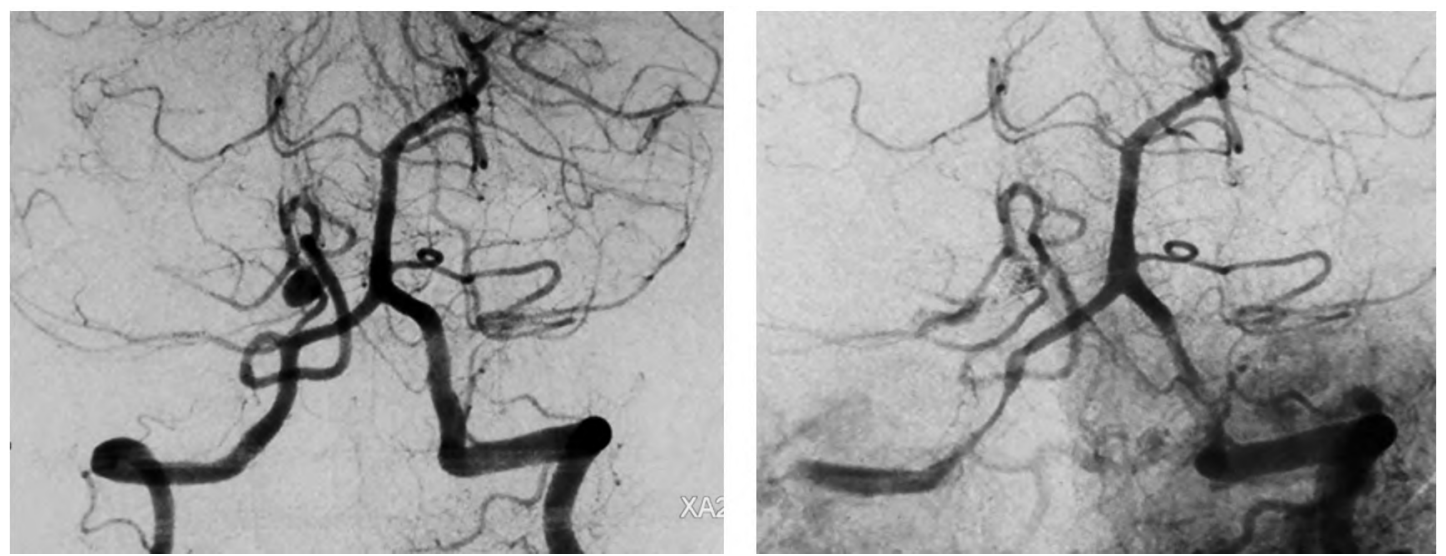

Case (4): A female patient aged 57 years, presented by sudden severe headache, disturbed conscious level (GCS 13) and repeated vomiting. CT brain showed SAH (fisher grade 2) and CT brain angiography showed Posterior Inferior Cerebellar Artery (PICA) aneurysm. Catheter angiography is done with measuring aneurysm neck diameter about $3.7 \mathrm{~mm}$, dome height $5.4 \mathrm{~mm}$ and aspect ratio is 1.45 . Patient is managed with simple coiling of aneurysm. With rupture aneurysm were occurred during procedure, managed by incomplete occlusion of aneurysm with Raymond class IIIa. Patient discharged with good GOS grade 5.

\section{Discussion}

One of the most vital and disabling outcomes associated with intracranial aneurysms is bleeding; thus, early surgical or endovascular treatment is recommended. Coil embolization is an established therapeutic procedure for both ruptured and unruptured intracranial aneurysms, and in many centers, this procedure is recommended as the first treatment option. All the series in the literature showed low morbidity and mortality rates of endovascular therapies [4].

Since the early era of detachable coil therapy, assessments of aneurysm geometry and its effect on treatment decisions and treatment outcomes have been in use [5]. The most common and well- studied geometric determinants of treatment decision and outcome have been dome-to-neck ratio or the maximum aneurysm dome width to neck diameter, and neck width [6]. Zubillaga et al., originally defined a "wide neck" as an absolute neck diameter of 4.0mm [7]. Debrun et al., defined "wide-neck" aneurysms as those with dome-toneck ratios of <2.0 [8]. These early definitions were created on the basis of success with endovascular coil therapy when the technique was in its infancy. Cloft et al., later noted that the technical advance of complex coil shapes allowed successful endovascular therapy of aneurysms with a dome-to-neck ratio of $>1.5$ [9]. These definitions predicted widespread use of major technical advances that allow successful coil therapy of wide-neck aneurysms, 
such as balloon remodeling and stent assistance [10].

A more practical modern approach to the definition of "wide-neck" or "difficult" aneurysm would be a definition that predicts the need to use adjunctive measures, such as balloons or stents, to treat the aneurysm safely. Furthermore, in addition to dome to neck ratio and neck width, other geometric factors may play a role in treatment decisions and outcomes. Aspect ratio, defined as aneurysm height-to-neck width, may play a role as a predictor of treatment outcomes and decisions. So with growing experience, advanced biplane imaging with rapid subtraction fluoroscopy and refinements of technique in the use of coiling, most brain aneurysms can be obliterated at a low complication rate [11].

This study was designed to obtain accurate correlation between the size of aneurysm necks with also associated Aspect Ratio and with the degree of aneurysm occlusion as seen on followup angiograms and with clinical outcome after endovascular intervention. All aneurysms were divided according to neck size into small neck aneurysms group $>4 \mathrm{~mm}$ and the other group with wide neck aneurysm $<4 \mathrm{~mm}$, and according to AR into group with $A R>2$, group with $A R$ 1.5-2, group with 1-1.5 and a group with $\mathrm{AR}<1$.

In this study, the small necked group with modified Raymond classification are; class I was achieved in $22(68.75 \%)$ aneurysms, class II in 8 $(25 \%)$ aneurysms, class IIIa in one $(3.1 \%)$ aneurysm, class IIIb in one (3.1\%) aneurysm. The wide necked group provides different results, class I was achieved in 4 (40\%) aneurysms, class II in 2 $(20 \%)$ patients, class IIIa in $3(30 \%)$ aneurysms and class IIIb in one (10\%) aneurysm.

According to AR with modified Raymond classification; a group with $\mathrm{AR}>2$ had shown class I in $15(78.9 \%)$ aneurysms, class II in $2(10.5 \%)$ aneurysms, class IIIa in $2(10.5 \%)$ aneurysms, no class IIIb was achieved. A group with AR 1.5-2 had shown class I in 9 (52.9\%) aneurysms, class II in $6(35.3 \%)$ aneurysms, class IIIa in $1(5.9 \%)$ aneurysms, class IIIb in $1(5.9 \%)$ was achieved. A group with AR 1-1.5 had shown class I in 2 (33.3\%) aneurysms, class II in $2(33.3 \%)$ aneurysms, class IIIa in $1(16.7 \%)$ aneurysms, class IIIb in $1(16.7 \%)$ was achieved. No patients in the study with AR $<1$.

In this study, endovascular coiling were accomplished by single microcatheter in 36 aneurysms, double microcatheter in 4 aneurysms, 2 balloon assisted, and no stent or flow diverters were used. single microcatheter technique was used in 30 small neck aneurysms and 6 wide neck aneurysms, according to AR; this technique was used in 19 aneurysms with $A R>2,15$ aneurysms with AR 1.5-2, and 2 aneurysms with AR 1-1.5. Double microcatheter technique were used in 2 small necked aneurysms and 2 wide necked aneurysms, according to AR; this technique was used in 2 aneurysms with AR 1.5-2, and 2 aneurysms with AR 1-1.5. balloon assisted technique were used in 2 wide necked aneurysms, according to AR; this technique was used in 2 aneurysms with AR 1-1.5.

The analysis of these results clearly indicates that the degree of aneurysm occlusion and the endovascular technique used is affected by the aneurysm neck size and its relation to dome height. This finding can be explained by taking into consideration the behavior of the occlusive material inside the lesion. In endovascular therapy a small neck holds the occlusive agent inside the aneurysm. Using the Guglielmi detachable coil technique, the smaller the neck the higher the probability that the mesh of coils bridges across the neck area. This allows aneurysm occlusion without the danger of herniation into the parent vessel and with little risk of coil migration.

Brinjikji et al., demonstrated that a low aspect ratio plays a more dominant role than either dome to neck ratio or neck diameter in predicting the need for adjunctive techniques in the coiling of intracranial aneurysms. Furthermore, aspect ratio is a significant independent predictor of the need for these adjunctive techniques. Also demonstrated that the coiling of intracranial aneurysms without adjunctive techniques such as stent placement and balloon remodeling is clinically favored for aneurysms with an aspect ratio $>1.6$, a dome to neck ratio $>1.6$, and a neck size $<4 \mathrm{~mm}$. Coiling with a adjunctive techniques is favored for aneurysms with dome to neck ratios $>1.6$, aspect ratios $>1.6$, and neck size $>4 \mathrm{~mm}$. analysis of these results goes with our study [11]

Standhardt et al., was achieved in 202 patients and had shown a significant link between neck size and occlusion rate. The occlusion rate was substantially higher in small neck aneurysms, in narrow neck aneurysms $77.1 \%$ complete, $18.1 \%$ neck remnant, $4.8 \%$ incomplete and in wide neck $35.8 \%$ complete, $51.6 \%$ neck remnant, $12.6 \%$ incomplete, this results goes with our study, with little difference in percentage related to little patients in our study [12]. 
Zubillaga et al., evaluated the relationship between the degree of occlusion after intra aneurysmal embolization using GDC and the neck size in 79 cases of intracranial aneurysms with complete occlusion was achieved in $85 \%$ of the aneurysms included in the small necked group. The remaining $15 \%$ of the aneurysms in this group showed residual aneurysm neck filling at the follow-up angiogram. The wide necked group provides significantly different results. Only $15.7 \%$ of the cases showed complete occlusion. In a much higher proportion $(84.3 \%)$, the occlusion was subtotal. The analysis of these results goes with our results in a group of small neck but with marked difference in wide neck group due to more advance in intervention related to imaging and assisted techniques as double microcatheter, balloon assisted, stent and overflow diverters [7].

Irie et al., was achieved in 22 patients with 22 aneurysms and had shown, complete occlusion in $70 \%$ of small aneurysms. The remaining $30 \%$ showed residual aneurysm with neck filling on follow-up angiogram. In the wide neck group, only $25 \%$ of the cases showed complete occlusion. Analysis of results goes with our results, but with some difference in wide neck group due to more advance in intervention techniques and materials [13].

In contrast to results of this study, Miri et al., reported that complete occlusion was achieved in $91.7 \%$ of small necked aneurysms, the remaining $8.3 \%$ showed subtotal occlusion. In the wide neck group, complete occlusion was achieved in $85 \%$ of aneurysms. The remaining $15 \%$ showed subtotal occlusion. Analysis of results there was no significant relationship between aneurysm neck size with total or subtotal occlusions , these results are relatively similar in small necked aneurysms, but marked differences in wide necked aneurysms due to usage of Neuroform stent with more safety for coiling without herniation to parent artery [14].

The wide difference of results between our study and Miri et al., series in treating wide neck aneurysms, suggested that the adjuvant endovascular technique had improved the efficacy of obliteration of wide neck aneurysms ,this explained our low results in wide neck aneurysms due to financial issuesas only 2 aneurysms out of 42 aneurysms were obliterated by an adjuvant endovascular assisted technique.

In this study, six procedures (15\%) were found to be complicated. The most common complications were aneurysm perforation (5\%), thromboembolic events (5\%), device induced vasospasm (5\%). In Standhardt H. et al., thirty-nine procedures (19.3\%) were found to be complicated. The most common complications were thromboembolic events $(10.9 \%)$, coil dislocation $(4.0 \%)$, and problems in connection with the vascular access sheath (1.5\%), device induced vasospasm (1.9\%), distal arterial perforation (1\%). This study were done on 202 patients [12]. In Willinsky et al., Aneurysm perforation $23(6.1 \%)$, parent vessel occlusion $15(4.0 \%)$, thromboembolic events 11 (2.9\%), mass effect 1 $(0.3 \%)$, arterial dissection $2(0.6 \%)$, parent vessel rupture $1(0.3 \%)$. This study were done on 377 patients [15]. In Miri et al., eleven patients (12.5\%) experienced complication during the procedure including $2(2.3 \%)$ distal perforation, 4 (4.5\%) thromboembolic events, 2 (2.3\%) mild to moderate vasospasms, and $3(3.4 \%)$ aneurysm perforation. This study were done on 88 patients [14].

In this study, no procedure-related mortality was recorded. One $(2.5 \%)$ patient with related mortality to global vasospasm. In Standhardt et al., the overall procedure-related mortality was $0.5 \%$ [14] . In Miri et al., there was no mortality during the procedure [14].

Good outcome (GOS 5) was achieved in 28 (70\%) patients, six patients $(15 \%)$ had moderate disability (GOS 4), 4 (10\%) patients with severe disability (GOS 3), one (2.5\%) patient were vegetative state (GOS 2) and one (2.5\%) patient were dead (GOS 1). In Willinsky et al., good outcome (GOS 5) was achieved in 278 patients (73.8\%). Thirty six patients $(9.5 \%)$ had moderate disability (GOS 4), 24 (6.4\%) patients with (GOS 3), 6 (1.6\%) patients with (GOS 2) and $33(8.7 \%)$ patients with (GOS 1) or a poor clinical outcome, and 33 patients $(8.8 \%)$ died. These results goes with our study except there were high mortality and sever disability in Willinsky et al., study, as in our study no cases with $\mathrm{H} \& \mathrm{H}$ grade 5 were included, and patients with $\mathrm{H} \& \mathrm{H}$ grade 4 were done after improvement of clinical condition [15]

In this study, among 34 patients with 36 aneurysms who underwent follow-up angiography after 6 months, 29 aneurysms $(80.6 \%)$ had no change, five $(13.9 \%)$ had recanalization and two (5.6\%) had further occlusion. 5 patients were missed and 1 patient were dead.

In D'Agostino et al., of the 76 aneurysms with a 6-month angiographic follow-up, four (5.3\%) revealed further occlusion, $54(71.1 \%)$ were unchanged, and $18(23.7 \%)$ showed recanalization [16]. In Miri et al., among patients who underwent 
control angiography, 34 aneurysms $(89.4 \%)$ had no change, two (5.3\%) had new growth and two $(5.3 \%)$ had widening of the neck after 6 months follow-up [14].

\section{Conclusion:}

The technique of endovascular occlusion with Guglielmi detachable coils was originally designed to offer a less traumatic therapy for intracranial aneurysms. The results of this study clearly confirm that complete occlusion of small-necked aneurysms and aneurysms with AR $>1.5$ can be achieved with simple coiling. The results obtained in the widenecked group and aneurysms with $\mathrm{AR}<1.5$ are less satisfactory. As noted above. Thus, coiling with adjunctive techniques as balloon or Neuroform stent and flow diverters, is favored for better results.

\section{Acknowledgment:}

The authors thank all included patients.

\section{Funding:}

This study had no funding from any resource.

\section{Competing interests:}

The authors declare that they have no conflict of interest.

\section{Ethical approval:}

This research accepted by Research Ethics Committee (REC) of Faculty of Medicine, Benha University (Chairman: Prof/Ibrahim El-Gendy).

All procedures performed in studies involving human participants were in accordance with the ethical standards of the institutional and/or national research committee and with the 1964 Helsinki declaration and its later amendments or comparable ethical standards. A written informed consent was obtained from each patient after explaining all steps of this study.

\section{Authors' contributions:}

Dr. Ahmed Deabes, Dr. Mohammed Shadad, performed the clinical part of the study, Dr. Ahmed Deabes, Dr. Ahmed Arab, Dr. Fathy, and Dr. Hossam Maaty analyzed the data and wrote with meticulous revision of the paper.

\section{References}

1- BROWN R.D. and BRODERICK J.P.: "Unruptured intracranial aneurysms: Epidemiology, natural history, management options, and familial screening", The Lancet Neurology, Vol. 13, No.4, pp. 393-404, 2014.

2- JOHN E. MENDOZA and ANNE L. FOUNDAS: The Cerebral Vascular System. Clinical Neuroanatomy: A Neurobehavioral Approach, pp. 501-43, 2008.
3- JOHNSTON S.C., RANDALL T., HIGASHIDA and DANIEL L.: Recommendations for the Endovascular Treatment of Intracranial Aneurysms, Stroke, 33: 2536-44, 2002.

4- BEKELIS K., GOTTLIEB D., SU Y., O'MALLEY A.J., LABROPOULOS N. and GOODNEY P.: Surgical clipping versus endovascular coiling for elderly patients presenting with subarachnoid hemorrhage. J. Neurointerv. Surg., 2015.

5- GONZALEZ N., SEDRAK M. and MARTIN N.: Impact of anatomic features in the endovascular embolization of 181 anterior communicating artery aneurysms. Stroke, 39: 2776-82, 2008

6- KIYOSUE H., TANOUE S. and OKAHARA: Anatomic features predictive of complete aneurysm occlusion can be determined with three-dimensional digital subtraction angiography. AJNR Am. J. Neuroradiol., 23: 1206-13, 2002 .

7- ZUBILLAGA A.F., GUGLIELMI G., VINUELA F. and GARY R.: Endovascular Occlusion of Intracranial Aneurysms with Electrically Detachable Coils: Correlation of Aneurysm Neck Size and Treatment Results; AJNR Am. J. Neuroradio., 15: 815-20, May 1994.

8- DEBRUN G.M., ALETICH V.A. and KEHRLI P.: Aneurysm geometry: An important criterion in selecting patients for Guglielmi detachable coiling. Neurol. Med. Chir. (Tokyo) 38 (Suppl): 1-20, 1998.

9- CLOFT H.J., JOSEPH G.J. and TONG F.C.: Use of three dimensional Guglielmi detachable coils in the treatment of wide necked cerebral aneurysms. AJNRA M J. Neuroradiol., 21: 1312-14, 2000.

10- PIEROT L., SPELLE L. and VITRY F.: Immediate clinical outcome of patients harboring unruptured intracranial aneurysms treated by endovascular approach: Results of the ATENA study. Stroke, 39: 2497-504. Epub 2008 Jul $10,2008$.

11-BRINJIKJI W., CLOFT H.J. and KALLMES D.F.: Difficult Aneurysms for Endovascular Treatment: Overwide or Undertall? AJNR Am. J. Neuroradiol., 30: 1513-17, 2009.

12- STANDHARDT H., SCHWARZ B., GRUBER A., BENESCH T. and KNOSP E.: Endovascular Treatment of Unruptured Intracranial Aneurysms With Guglielmi Detachable Coils; Short- and Long-Term Results of a SingleCentre Series, Stroke, 39: 899-904, 2008.

13- IRIE K., TAKI W., NAKAHARA I., SAKAI N. and ISAKA F.: Intra-aneurysmal Occlusion of Cerebral Aneurysms Using Detachable Coils, Correlation of Aneurysm Neck Size and Treatment Results, Interventional Neuroradiology, 3 (Suppl 2): 114-7, 1997.

14- MIRI M., GHANAATI H., SALAMATI P. and EBRAHIMI N.: Coil Embolization of Intracranial Aneurysms: A Six Month Follow-up Study, Iran J. Radiol., 12 (3): e109862, 2015.

15- WILLINSKY J., PELTZ L., DA COSTA R., AGID R.I. and FARB K.G.: Clinical and Angiographic Follow-up of Ruptured Intracranial Aneurysms Treated with Endovascular Embolization, AJNR Am. J. Neuroradiol., 30: 103540; May 2009.

16- D'AGOSTINO S.J., HARRIGAN M.R., CHALELA J.A and NICHOLAS J.S.: Clinical experience with Matrix2 360 degrees coils in the treatment of 100 intracranial aneurysms. Surg. Neurol., 72 (1): 41-7, 2009. 


\section{العلاقة بين القسطرة التداخلية كوسيلة لعلاج التمددات الشريانية المخية وبين النتائج بعد القسطرة}

ينقسم التمدد الشريانى بالمخ إلى تمدد تكيسى وهو الآكثر إنتشارا . ويتكون من قبه وعنق يربط بين القبه والشريان الذى ينشاً منه هذا

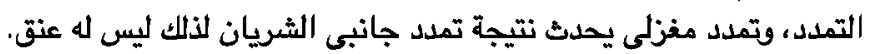

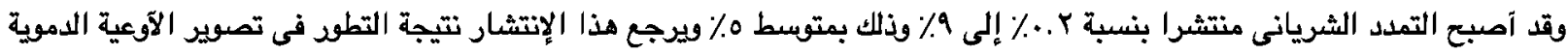

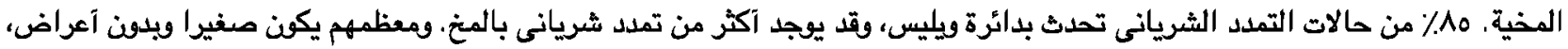

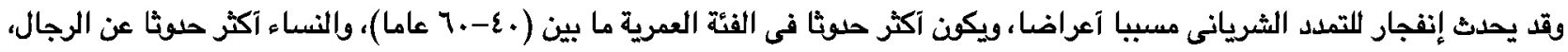

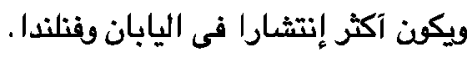

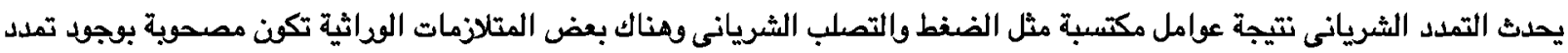

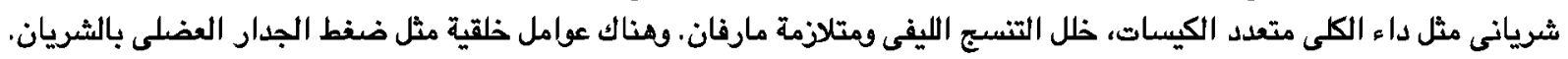

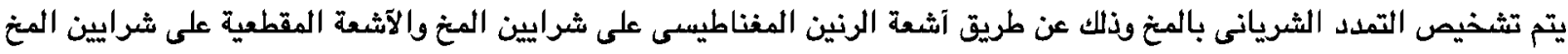

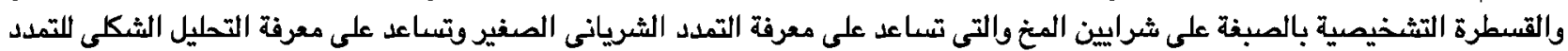

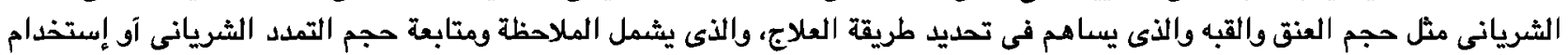
قسطرة تداخلية علاجية آو إستخدام المشبك الجراحى لفلق هذا التمدد الشريانى.

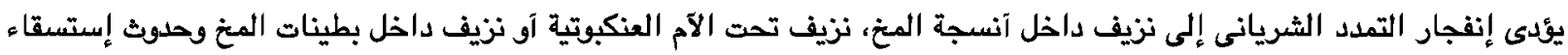

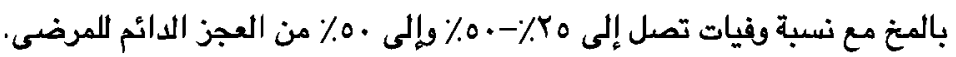

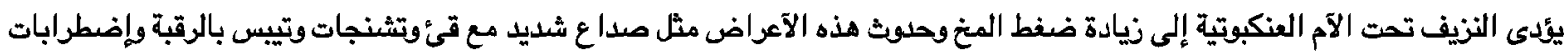

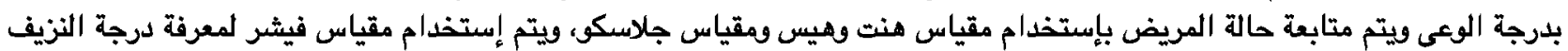

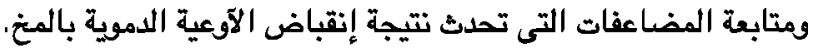

والهدف من الدراسة الحالية هو تقييم العلاقة بين القسطرة التداخلية كوسيلة لعلاج التمددات الشريانية المخية وبين النتائج بعد القسطرة

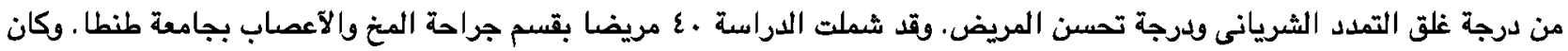

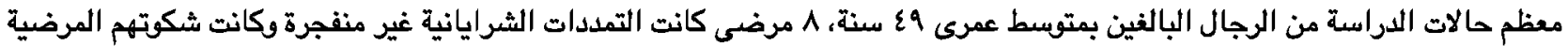

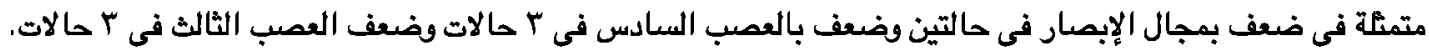

وهناك ب مريضا كانت التمددات الشريانية منفجرة، وتم تقييم هؤلاء المرضى بمقياس هنت وهيس وكانت كالآتى ^ مرضى من من الدرجية

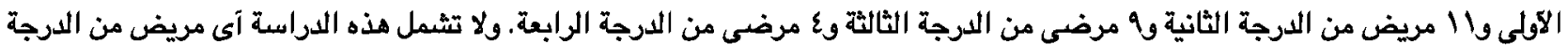

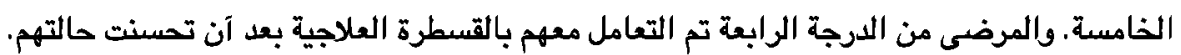

الفحص الفويى الذى تم لهذه الحالات هو الآشعة المقطعية على المخ والتى آظهرت موضع وحجم ونوع النزيف الناتج عن إنفجار التمدد

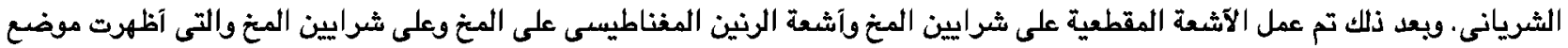

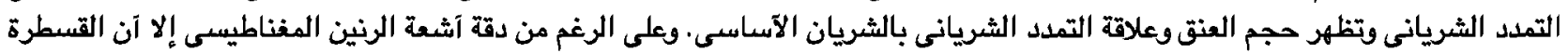

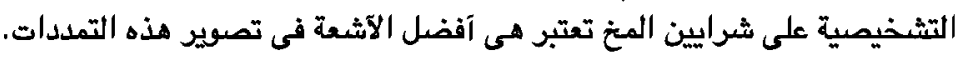

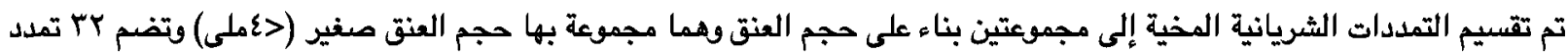

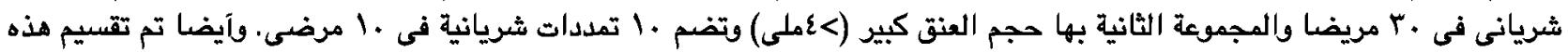

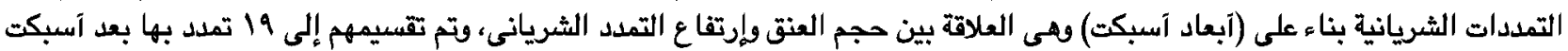

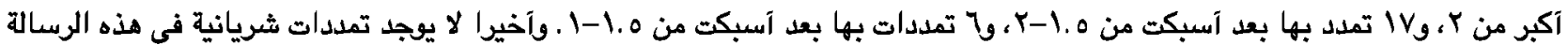

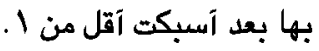

وقد تم إنصمام هذه التمددات الشريانية عن طريق القسطرة الشريانية ويإستخدام ملفات دقيقة من البلاتيوم وتمت بإستخدام قسطرة

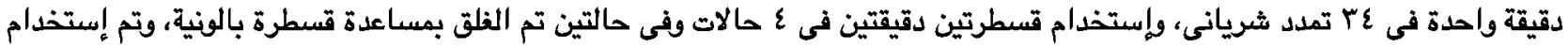

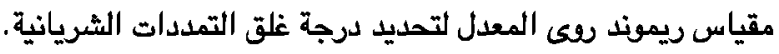




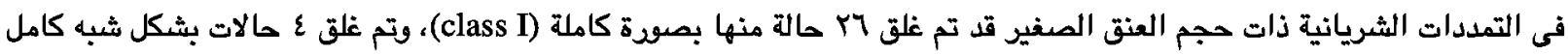
مع وجود جزء من العنق، وحالتين تم غلقهم بشكل غير كامل (class II) الكيير تم غلق التمدد بصورة كاملة فى ع حالات (class I)، وبشكل شبه كامل فى حالتين (class II) وبشكل غير كامل في ع حالات (class IIIb)

.(3-class IIII \& 1

وكذلك آهم المضاعفات الناتجة عن النزيف الحادث (تحت الآم العنكبوتية وداخل بطينات ونسيج المخ) بسبب إنفجار التمددات هو حدوث

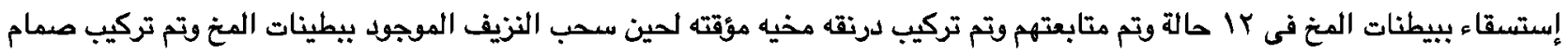

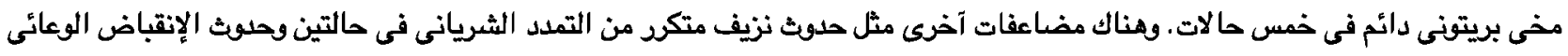

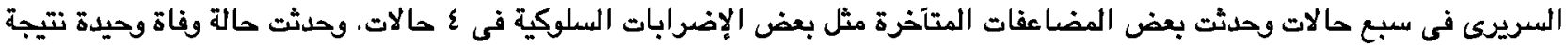
الإنقباض الكلى للآّعية الدموية المخية.

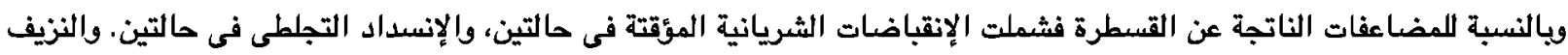

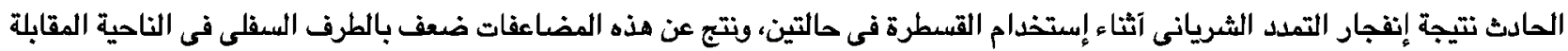

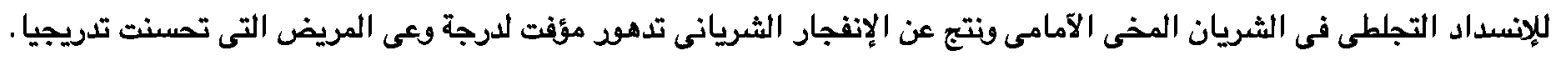

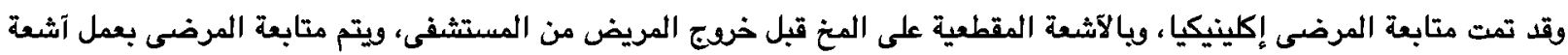

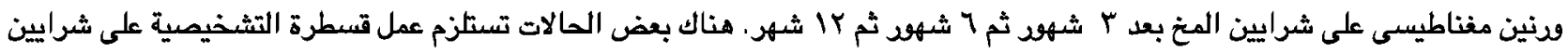

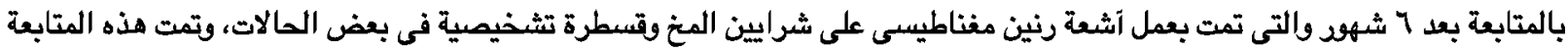

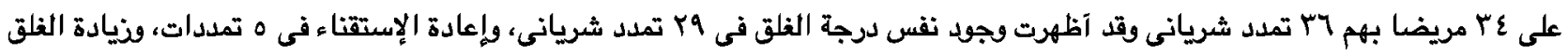

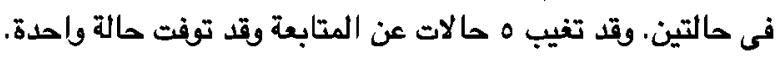

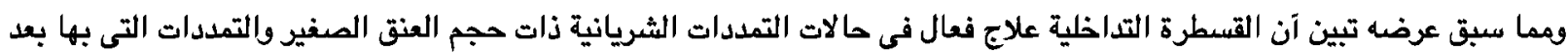

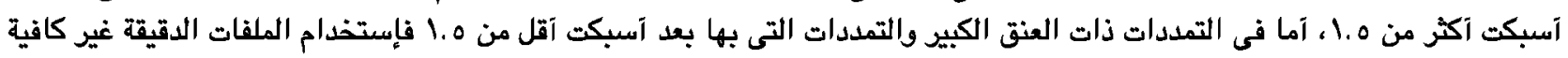

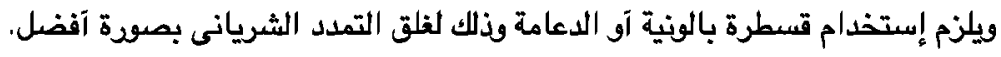

